\title{
Soetomo Covid-19 Score As An Early Identification Tools of Covid-19 Patients in Surabaya, Indonesia
}

\author{
Vininsia Merry Laura Mesang ${ }^{1}$, Retno Asih Setyoningrum ${ }^{1}$, Anang Endaryanto ${ }^{1}$, \\ Risky Vitria Prasetyo ${ }^{1}$
}

official email address: lauramesang@gmail.com 1 Department of Child Health Faculty of Medicine Universitas Airlangga Dr. Soetomo General Hospital, 60286, Surabaya, Indonesia.

\begin{abstract}
Background Clinical prediction scores support the assessment of patients to limit the COVID-19 outbreak. Soetomo COVID-19 Score (SCS) has been used to determine further diagnostic and patient zoning purposes in our hospital. We aimed to evaluate the SCS characteristics and its capability to determine those with COVID-19 infection.

Methods The score was evaluated using retrospective analysis from March 2020 to January 2021, which was undertaken on patients who had taken SARS CoV-2 PCR swab at Dr. Soetomo General Hospital, Surabaya. Descriptive, Chi-Square, and Mann-Whitney tests were analysed to evaluate the comparison among PCR SARS CoV-2 swab results. Receiver operating characteristic was carried out to determine the SS discrimination capability.

Results Of 454 subjects participating in the study, $32.8 \%$ of them were confirmed COVID-19. They had a lower leukocyte level and a higher median total of SCS $\left(10010 \pm 9448\right.$ cells $\left./ \mathrm{mm}^{3}\right)$. Most of the SCS characteristics showed significant results according to the swab results. SCS had a good discrimination capacity (AUC 82.5\%, 95\% CI 78.2-86.8\%; $\mathrm{p}<0.001$ ). Total SCS 12.5 was the optimal cut-off point to discriminate suspected COVID-19 patients with good sensitivity $(89.3 \%)$ and specificity $(78.4 \%)$.
\end{abstract}

Conclusions The newly developed SCS is a considerable tool for an early COVID-19 patients identification.

Keyword : Covid-19 Score, Diagnosis, RT-PCR Swab, Screening Tool, Soetomo Covid-19 Score. 


\section{Introduction}

Corona Virus Disease 2019 (COVID-19) has spread globally and over 4,000,000 people have been infected since early December 2019 [1]. As July $15^{\text {th }}$, 2020, the Indonesian government announced that there were 80,094 confirmed cases of COVID-19 and 3,797 deaths [2]. Surabaya as the second largest city in Indonesia was in the first position for the number of COVID-19 infections, where there were 18,545 confirmed positive cases of COVID-19, 9,717 recovered patients $(51.03 \%)$, and 1,433 died patients $(7.65 \%)$ as of July $20^{\text {th }}, 2020$ [3]. The diagnosis of COVID-19 counts on the detection of SARS-CoV-2 nucleic acid. Though, as a result of the lack of incorrect negative results and the relatively inadequate detection kits, numerous patients cannot be identified early [4]. The crucial problem found at the triage level in out hospital at the beginning of the pandemic was determining which patients needed a SARSCoV2 PCR swab examination as well as patient zoning for isolation room treatment to limit the SARS-CoV-2 infection [5].

A scoring system to increase the detection rate along with its detection speed of infected patients is urgently needed at this time. So that early identification, isolation, and care to limit the other spread of the virus can be achieved properly [4]. Our hospital is currently uses a scoring system primarily for the safety of staff and the hospital environment. The Soetomo COVID-19 Score (SCS) was carried out by using a quick history and physical examination and other available objective data to quickly determine the level of risk of COVID-19 [5]. The current study aimed to analyse the characteristics of patient with COVID-19 and the score discrimination ability of SCS as a multi-parameter scoring system for patients with suspected COVID-19.

\section{Subjects and Methods}

\subsection{Study Population and Design}

This cross-sectional study was done from March $1^{\text {st }}, 2020$ to January $31^{\text {st }}, 2021$ on patients who experienced SARS CoV-2 RT-PCR swab at Dr. Soetomo General Hospital, Surabaya. A proportional sampling technique was undertaken using the prevalence of COVID-19 data according to age group in Indonesia [6]. All patients with positive and negative SARS CoV-2 PCR swab were classified into COVID-19 group and non-COVID-19 group. The data were obtained from patients who treated at COVID-19 isolation room. Non-COVID-19 group was those who had a negative SARS CoV-2 RT-PCR swab results carried out in emergency room. Due to data limitation, this study only included patients from Pediatric and Internal Medicine Department. Neonatal and patients from other departments were excluded. The study was approved by the Health Research Ethics committee of the hospital (Ref.NO.0280/LOE/301.4.2/I/2021).

\subsection{Soetomo COVID-19 Score}

Soetomo Covid-19 Score consisted of 22 questions (Q), which were divided into a major and minor score (Table 2). Patient experiencing at least one of the major criteria (Q1-Q3) would be scored 20. Whereas minor SCS consisted of four questions regarding epidemiological and exposure history (Q4-Q7) (at least having one assessment with score 4), four questions regarding symptoms (Q8-Q11) (at least having one assessment with score 4), ten questions (Q12Q21) regarding comorbidity, laboratory, and radiology results (one score of each assessment), and one question (Q22) regarding contact history with confirmed COVID-19 patient (without standard PPE) (score 10) [5]. The patient does not need to meet all the criteria to be included in this study. The SCS assessment was carried out at the first time when the patient enters the hospital.

\subsection{Laboratory and Radiology}

COVID-19 identification was achieved by the result of the real-time reverse transcription-polymerase chain reaction (RT-PCR) assay for SARS-CoV-2, that was conducted by the Microbiology Department, Faculty of Medicine, Airlangga University, Surabaya. Laboratory and radiology values included platelet, leucocyte, neutrophil to lymphocyte (NLR) count, absolute lymphocyte count (ALC), C-reactive protein (CRP), chest X-ray and chest Ct scan. Assessment of the laboratory and radiology results were carried out at the first examination when the patient entered the hospital. 


\subsection{Statistical Analysis}

Continuous variables were presented as medians and interquartile ranges (IQR). Categorical variables were transcribed in numbers and percentages. Comparison tests of standard characteristics for continuous variables and ordinal variables were completed using Mann-Whitney test. The SCS characteristics were examined using a Chisquare test and its distribution according to total SCS were presented using box plot figure. The SCS discrimination capacity and optimal cut off were determined by determining the area under the receiver operating characteristic (AUROC) curve. SPSS software version 21.0 were used to process the data. $P<0.05$ was assumed statistically significant.

Table 1. Baseline characteristics

\begin{tabular}{|c|c|c|c|c|}
\hline \multirow[b]{2}{*}{ Characteristics } & \multicolumn{2}{|c|}{ Swab PCR SARS CoV-2 } & \multirow[b]{2}{*}{$\begin{array}{l}\text { Total } \\
(N=454)\end{array}$} & \multirow[b]{2}{*}{$p$} \\
\hline & $\begin{array}{l}\text { Positive } \\
(N=149)\end{array}$ & $\begin{array}{c}\text { Negative } \\
(N=305)\end{array}$ & & \\
\hline Age Med \pm IQR (years) & $50 \pm 17$ & $43 \pm 26$ & $43 \pm 27$ & 0.304 \\
\hline Age Group $N(\%)$ & & & & 0.999 \\
\hline 1 month-5 years & $3(2.0)$ & $7(2.3)$ & $10(2.2)$ & \\
\hline$>5-18$ years & $9(6.0)$ & $17(5.6)$ & $26(5.7)$ & \\
\hline$>18-30$ years & $32(21.5)$ & $66(21.6)$ & $98(21.6)$ & \\
\hline$>30-45$ years & $43(28.9)$ & $89(29.2)$ & $132(29.1)$ & \\
\hline$>45-60$ years & $42(28.2)$ & $82(26.9)$ & $124(27.3)$ & \\
\hline$>60$ years & $20(13.4)$ & $44(14.4)$ & $64(14.1)$ & \\
\hline Gender $N(\%)$ & & & & $0.020^{*}$ \\
\hline Male & $80(53.7)$ & $196(64.3)$ & $276(60.8)$ & \\
\hline Female & $69(46.3)$ & $109(35.7)$ & $178(39.2)$ & \\
\hline \multicolumn{5}{|l|}{ Laboratory result $(\mathrm{Med} \pm \mathrm{IQR})$} \\
\hline Platelet $\left(\right.$ cell $\left./ \mathrm{mm}^{3}\right)$ & $229000 \pm 182500$ & $286000 \pm 208500$ & $254500 \pm 183500$ & 0.224 \\
\hline Leucocyte $\left(\right.$ cell $\left./ \mathrm{mm}^{3}\right)$ & $10010 \pm 9448$ & $12300 \pm 10080$ & $10620 \pm 9310$ & $0.003^{*}$ \\
\hline Neutrophil to lymphocyte ratio & $6.4 \pm 7.6$ & $5.8 \pm 6.0$ & $5.5 \pm 6.3$ & 0.557 \\
\hline Absolute lymphocyte count & $1105 \pm 840$ & $1150 \pm 960$ & $1200 \pm 950$ & 0.565 \\
\hline C-Reactive protein & $7.2 \pm 10.5$ & $4.0 \pm 10.8$ & $5.3 \pm 11.3$ & 0.122 \\
\hline Comorbid disease $\mathrm{N}=303(\%)$ & $114(76.5)$ & $189(62.0)$ & $303(66.7)$ & $0.002^{*}$ \\
\hline Type of comorbid N $=220(\%)$ & & & & 0.368 \\
\hline Hypertension & $19(17.5)$ & $23(16.5)$ & $38(17.3)$ & \\
\hline Diabetes Mellitus & $21(25.9)$ & $28(20.1)$ & $49(22.3)$ & \\
\hline Malignancy & $17(21.0)$ & $25(18.0)$ & $42(19.1)$ & \\
\hline Cardiac Disease & $5(6.2)$ & $5(3.6)$ & $10(4.5)$ & \\
\hline Chronic kidney disease & $14(17.3)$ & $26(18.7)$ & $40(18.2)$ & \\
\hline Autoimmune & $4((4.9)$ & $13(9.4)$ & $17(7.7)$ & \\
\hline Obesity & $2(2.5)$ & $2(1.4)$ & $4(1.8)$ & \\
\hline Others & $3(3.7)$ & $17(12.2)$ & $20(9.1)$ & \\
\hline Total comorbid $n=303(\%)$ & & & & 0.637 \\
\hline 1 & $81(71.1)$ & $139(73.5)$ & $220(72.6)$ & \\
\hline$\geq 2$ & $33(28.9)$ & $50(26.5)$ & $83(27.4)$ & \\
\hline
\end{tabular}

SCS = Soetomo covid-19 score; Med= Median; IQR = interquartile range. Type of comorbid describes patients who have one type of comorbidity. Percentages are presented based on the total of each group, respectively positive SARS Cov-2 PCR swabs, negative and total subjects.

*) $p<0.05$ is assumed as statistically significant

\section{Results}

\subsection{Baseline characteristics}

A total of 454 patients included in this study. They were $149(32.8 \%)$ patients with positive and $305(67.2 \%)$ were negative SARS CoV-2 PCR swab. In the COVID-19 group, female were outnumbered than male (46.3\% and 53.7\%). Patients in the COVID-19 group had a higher age distribution (median 50 \pm 17 ) than the non-COVID-19 group (43 \pm 26 years). The proportion of children age $<18$ month in the COVID-19 group was found only in $8 \%$. Patients in the COVID-19 group had a lower median leukocyte $\left(10010 \pm 9448 \mathrm{cell} / \mathrm{mm}^{3}\right)$ compared to those in the non-COVID-19 
group $\left(12300 \pm 10080 \mathrm{cell} / \mathrm{mm}^{3}, p=0.003\right)$. In contrast, there were insignificant values of platelets, NLR, CRP, and ALC between the two groups. A total of 303 subjects had a comorbid disease, of which 83 of them had more than 1 type of comorbid. Diabetes mellitus was the most type of comorbid founded in the COVID-19 group compare to the non-COVID-19 group, respectively $25.9 \%$ and $20.1 \%$ (Table 1 ).

Table 2. The Soetomo Covid-19 Score Characteristics

\begin{tabular}{|c|c|c|c|c|}
\hline \multirow[b]{2}{*}{ Characteristics } & \multicolumn{2}{|c|}{ Swab PCR SARS CoV-2 } & \multirow[b]{2}{*}{$\begin{array}{c}\text { Total } \\
(N=454)\end{array}$} & \multirow[b]{2}{*}{$p$} \\
\hline & $\begin{array}{c}\text { Positive } \\
N=149(\%)\end{array}$ & $\begin{array}{l}\text { Negative } \\
N=\mathbf{3 0 5}(\%)\end{array}$ & & \\
\hline \multicolumn{5}{|l|}{ Major Soetomo Covid-19 Score } \\
\hline $\begin{array}{l}\text { Q1: (S/O) History of contact with confirmed COVID-19 patients (without } \\
\text { standard personal protective equipment) PLUS } \geq \text { objective minor findings }\end{array}$ & $34(22.8)$ & $3(1.0)$ & $37(8.1 \%)$ & $<0.001 *$ \\
\hline Q2: (O) Chest X-ray: Basal bilateral opacity & $53(35.6)$ & $23(7.5)$ & $76(16.7)$ & $<0.001 *$ \\
\hline Q3: (O) Chest Ct-Scan: Ground glass opacity & $10(6.7)$ & $15(4.9)$ & $25(5.5)$ & 0.432 \\
\hline \multicolumn{5}{|l|}{ Minor Soetomo Covid-19 Score } \\
\hline $\begin{array}{l}\text { Q4:(S) Work/attend mass gatherings/places of worship/social gathering/ fast/markets } \\
\text { or service places (airports, banks, etc.) }\end{array}$ & $8(5.4)$ & $19(6.2)$ & 27(5.9) & 0.716 \\
\hline $\begin{array}{l}\text { Q5:(S) Living or traveling in an area/community that has been infected (domestic and } \\
\text { overseas) }\end{array}$ & $143(96.0)$ & $274(89.8)$ & $417(91.9)$ & $0.025^{*}$ \\
\hline Q6:(S) Go out/work/living/ travel to positive/risky cases & $15(10.1)$ & $7(2.3)$ & $22(4.8)$ & $<0.001^{*}$ \\
\hline Q7:(S) Confirmed cases on surrounding environment (residence /work place) & $17(11.4)$ & $12(3.9)$ & $29(6.4)$ & $0.002 *$ \\
\hline Q8:(S/O) Fever/History of fever in the last 14 days $\left(\geq 37.5^{\circ} \mathrm{C}\right)$ & $84(56.4)$ & $127(41.6)$ & $211(46.5)$ & $0.003 *$ \\
\hline Q9:(S/O) Anosmia & $11(7.4)$ & $2(0.7)$ & $13(2.9)$ & $<0.001^{*}$ \\
\hline Q:10(S/O) Gastrointestinal symptoms (Diarrhoea/ Nausea/ Vomiting/ Abdominal pain) & $70(47)$ & $121(39.7)$ & $191(42.1)$ & 0.139 \\
\hline Q11:(S/O) Respiratory symptoms (Cough/runny nose/dyspnea) & $107(71.8)$ & $163(53.4)$ & $270(59.5)$ & $<0.001 *$ \\
\hline $\begin{array}{l}\text { Q12:(O) Co-morbid factors (Diabetes mellitus/ Hypertension /Chronic kidney disease/ } \\
\text { Malignancy / Autoimmune / Heart disorders / Obesity / Pregnancy) }\end{array}$ & $114(76.5)$ & $189(62.0)$ & $303(66.7)$ & $0.002 *$ \\
\hline Q13: (O) Leukopenia $\left(<5000\right.$ cell $\left./ \mathrm{mm}^{3}\right)$ & $25(16.8)$ & $20(6.6)$ & $45(9.9)$ & $0.001 *$ \\
\hline Q14: (O) Neutrophil to Lymphocyte Ratio $>3.5$ & $109(73.2)$ & $232(76.1)$ & $341(75.1)$ & 0.501 \\
\hline Q15: (O) Absolute Lymphocyte Count $<1100$ & $67(45.0)$ & $128(42.0)$ & $195(43.0)$ & 0.544 \\
\hline Q16: (O) Thrombocytopenia $(<180.000)$ & $49(32.9)$ & $66(21.6)$ & $115(25.3)$ & $0.010 *$ \\
\hline Q17: (O) C-Reactive Protein ( $>5 \mathrm{x}$ normal) & $66(44.3)$ & $89(29.2)$ & $155(34.1)$ & $0.001^{*}$ \\
\hline Q18: (O) Chest X-ray: Bilateral opacity (peripheral basal) & $34(22.8)$ & $37(12.1)$ & $71(15.6)$ & $0.003 *$ \\
\hline Q19: (O) Chest X-ray: Diffuse bilateral opacity & $15(10.1)$ & $60(19.7)$ & $75(16.5)$ & $0.010^{*}$ \\
\hline Q20: (O) Chest X-ray: Unilateral opacity & $19(12.8)$ & 41(13.4) & $60(13.2)$ & 0.838 \\
\hline Q21: (O) Chest X-ray: Central bilateral opacity & $33(22.1)$ & $41(13.4)$ & $74(16.3)$ & $0.018^{*}$ \\
\hline $\begin{array}{l}\text { Q22: (S) History of contact with confirmed COVID-19 patient (without standard PPE) } \\
\text { WITHOUT other findings }\end{array}$ & $17(11.4)$ & $3(1.0)$ & $20(4.4)$ & $<0.001 *$ \\
\hline
\end{tabular}

$\overline{\mathrm{S}}=$ subjective, $\mathrm{O}=$ objective, $\mathrm{S} / \mathrm{O}=$ subjective/objective, $\mathrm{CT}=$ Computerized tomography. Data are shown in $N(\%)$, and percentages are presented based on the total of each group, respectively positive SARS Cov-2 PCR swabs, negative and total subjects. $\left.{ }^{*}\right) p<0.05$ was considered statistically significant

\subsection{Soetomo COVID-19 Score Characteristics}

Subjects in COVID-19 group were dominated by patients with a history of confirmed COVID-19 contacts without PPE standard (plus objective minor findings) $(22.8 \%$ vs $1.0 \%, p<0.001)$, a history of living/traveling to infectious areas $(96 \%$ vs $89.8 \%, p=0.025)$, going out/one home/working/traveling to positive or at-risk cases $(10.1 \% v s 2.3 \%$, $p<0.001$ ), a surrounding environment with confirmed cases (residence and work place) $(11.4 \% v s 3.9 \%, p=0.002)$, and a history of contact with confirmed COVID-19 patients (without standard PPE) without other findings (11.4 vs $1.0 \%, p<0.001)$. In contrast, there were insignificant differences in $5.9 \%$ of subjects who had a history of working in/attending crowded places (Table 2).

Compare to non-COVID-19 group, those with COVID-19 were more symptoms of fever (56.4 vs $41.6 \%, p=$ 0.003 ), anosmia (7.4\% vs $0.7 \%, p<0.001)$, and respiratory symptoms (cough/cold/shortness of breath) $(71.8 \% v s$ $53.4 \%, p<0.001)$. Whereas, gastrointestinal symptoms showed insignificant results. Comorbidities were found to be more dominant in COVID-19 group $(76.5 \%$ vs $62.0 \%, p=0.002)$. More patients in COVID-19 group showed leukopenia $<5000$ cells $/ \mathrm{mm}^{3}(16.8 \%$ vs $6.6 \%, p<0.001)$, thrombocytopenia $(32.9 \%$ vs $21.6 \%, p=0.010)$, and an increase in CRP $>5 \mathrm{x}$ normal $(44.3 \%$ vs $29.2 \%, p<0.001)$. From the radiological aspect, patients with COVID-19 group were dominated with bilateral basal opacity chest $\mathrm{x}$-ray $(35.6 \% v s 7.5 \%, p<0.001)$, basal peripheral opacity $(22.8 \% v s$ 
$12.1 \%, p<0.003)$, and central bilateral opacity (22.1 vs $13.4 \%, p=0.018)$. In contrast, more patient with bilateral diffuse opacity were dominated in non-COVID-19 group $(19.7 \%$ vs $10.1 \%, p=0.010)$. Whereas, the CT scan of the GGO and unilateral opacity chest X-ray showed insignificant results (see Table 2).

\subsection{Discrimination ability}

The AUC value of total SCS to positive swab was $82.5 \%$ (95\%CI 78.2-86.8; $p<0.001)$, which indicated that its ability to discriminate against COVID-19 was considered good. The optimal cut off was 12.5 with sensitivity of $89.3 \%$ and specificity of $78.4 \%$ (Figure 1 ).

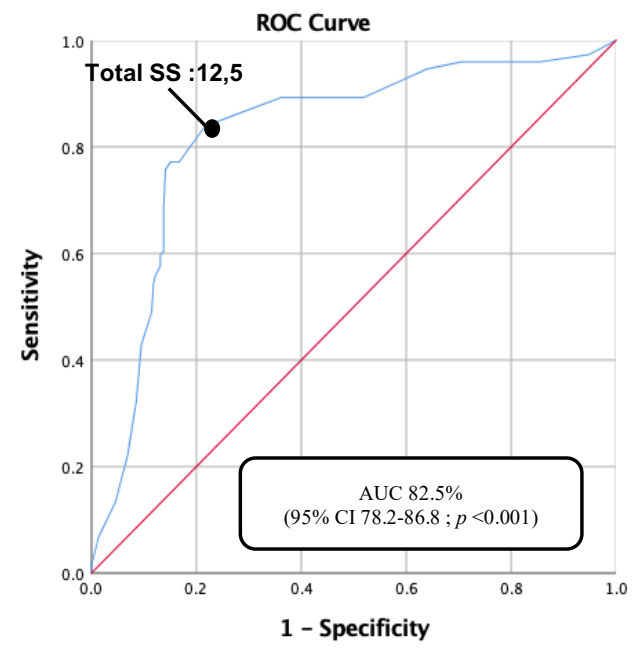

Figure 1 ROC Analysis of Total SCS to RT-PCR SARS CoV-2 Swab

\section{Discussion}

The global occurrence of COVID-19 was increasing as the major frontline in the first stage, prompt identification and success isolation of patients, and close interactions had made its spread in China so far under success control. Nevertheless, the reality showed that identification of potentially suspected patients remained challenging $[7,8]$. The SCS was the first COVID-19 screening-based score implemented at our hospital [5].

In terms of gender, our results were consistent with the community-based study conducted by Karyono and Wicaksana (2020) in Indonesia that the proportion of men dominated as much as $54.6 \%$ compared to women, and women showed a higher cure rate than men respectively [6,9]. The low proportion of children in this study was consistent with reports from several countries where most of them indicated that paediatric patients represented a marginal proportion of COVID-19 cases [10]. The CDC and Prevention in March 2020 confirmed that only 2\% of cases of COVID-19 were found in children younger than 19 years [11].

In the present study, working in/attending crowded places did not have a significant difference to the SARS CoV2 PCR swab. Whereas other contact history points were found to be significant and were dominated by the confirmed COVID-19 group. These findings prove that attending large events could either increase or decrease virus transmission. Indoor events are riskier than outdoor events, duration, being within 6 feet among others, and related risky behaviour such as singing, shouting, not maintaining physical distance, or not wearing masks could increase the risk of transmission [11]. In addition, a significant reduction of infection were found in the use of face masks and alcohol-based hand disinfectants [12].

In terms of clinical manifestations, anosmia was only found in $7 \%$ of subjects. On the contrary, other study stated anosmia were found in $47 \%$ and $86 \%$ of subjects [13]. Moreover, respiratory tract symptoms (i.e. cough/runny nose/shortness), fever, and gastrointestinal symptoms were the dominant symptoms, $71.8 \%, 56.4 \%$, and $47 \%$ of COVID-19 subjects respectively. Fever was found in $43.8 \%$ of patients, and febrile symptoms developed in $88.7 \%$ of patients after hospitalization [14]. 
The leukocyte levels in subjects with COVID-19 were significantly lower than non-COVID-19 group. Song C et al.(2020) reported the same but with a lower median leukocyte $\left(5.3 \times 10^{9} v s 6.8 \times 10^{9}, p<0.001\right)$ in COVID-19 group [4]. However, a study of 140 COVID-19 patients in China indicated that the leukocyte was in the normal range in $68.1 \%$ of patients, escalated in $12.3 \%$ of patients, and declined in $19.6 \%$ of patients [15]. The rate of leukopenia in COVID19 patients could vary in each phase of the disease. During the initial stages of COVID-19 when the patient was still asymptomatic, the white blood cell and peripheral blood lymphocyte counts might be normal or reduced to some extent but those signs might alter as the disease progresses, and during the incubation period (1-14 days) and the initial period of the disease, when nonspecific indications appeared, peripheral blood leukocyte lymphocyte levels might be normal or minimally decreased [16].

This study reported that patients with confirmed COVID-19 had varying results of chest X-rays. More patients with basal bilateral, basal peripheral, and central bilateral opacity were found in COVID-19 group, whereas bilateral diffuse opacity was found to be more dominant in the negative group. Some initial radiological studies stressed the function of radiological imaging in the initial identification and controlling of COVID-19, but the variability of chest X-ray results in COVID-19 patients was a major constraint faced, which could increase the rate of incorrect positive and negative results [17]. The proportion of GGO thoracic CT scans was founded in few patients. In contrast, there was a study reported that the sensitivity of chest radiographs increased during COVID-19 contagion, from 55\% at 2 days to $79 \%$ at 11 days after symptom started, and sequential chest radiographs approached the diagnostic accurateness (AUC 0.875 vs 0.916). In addition, GGO CT scan was found in 88\% of patients with positive COVID-19 (OR 7.7; $95 \%$ CI 3.3-17.7, $p<0.001)$ [18].

A scoring system to increase the detection rate and speed of detection of infected patients was urgently needed at this time. However, the scoring system currently used was more directed to the COVID-19 severity. Another scoring system reported that a total score of four was sufficient to initiate special approaches and care for high-risk patients [16,19]. Whereas Song C et al.(2020) using an easy parameter called the Early Warning Score (EWS) with a total score limit of 10 for the detection of highly potential patients with a much higher AUC value than the present study $(0.956,95 \%$ CI $0.934-0.978, p<0.001)$ [4].

This study confirmed that SCS used since the early pandemic at our hospital had a good COVID-19 discriminating capability with cut off of 12.5 . However, several points were found to be insignificant that should be further evaluated. There were several limitations in this study. As in other retrospective studies, retracing medical record data had several limitations regarding data collection and inadequate data entry completeness that might lead to recall bias. The high variability of symtoms and laboratory findings in children and adults without an onset period of symptoms evaluation might be the confounding factor of the present study. Despite several limitations, this study provided important information considering the capability of SCS in discriminating COVID-19 patients, which was easy to apply in every health care facility in Indonesia, especially in areas with limited SARS CoV-2 PCR swab examination kits.

\section{Conclussion}

The newly developed SCS is a considerable tool for an early COVID-19 patients identification and is useful for zoning patients to prevent the explosion of COVID-19 infection in hospital setting.

\section{Acknowledgement}

We would like to thank Miss Fika Amalia for her assistance in data collection. The authors disclosed receipt of the following financial support for the research, and/or publication of this article.

\section{Financial Support}

This research received no specific grant from any funding agency, commercial or not-for-profit sectors.

\section{Conflict of Interest}

None. 


\section{Ethical Standard}

This study obtained permission from the ethics committee. Ethical approval was obtained from the Institutional Ethical Committee of Dr. Soetomo general hospital (Ref.NO.0280/LOE/301.4.2/I/2021).

\section{Acknowledgements}

We would like to thank Miss Fika Amalia for her assistance in data collection. The authors disclosed receipt of the following financial support for the research, and/or publication of this article.

\section{References}

1. Dhama K, Khan S, Tiwari R, et al. Coronavirus disease 2019-COVID-19. Clin Microbiol Rev $2020 ; 33$ :e00028-20.

2. World Health Organization. Coronavirus disease 2019 situation report, 2020. https://cdn.who.int/media/docs/defaultsource/searo/indonesia/covid19/who-situation-report-14.pdf. (Accessed August 20 ${ }^{\text {th }}, 2020$ ).

3. East Java Provincial Government, Map of the spread of Covid-19 in the city of Surabaya, Surabaya, 2020. https://awancovid19.surabaya.go.id/visualisasi/graph. (accessed July 20 ${ }^{\text {th }}, 2020$ ).

4. Song C, Xu J, He J and Lu Y. Covid-19 early warning score: a multi-parameter screening tool to identify highly suspected patients. medRix 2020; 200319006.

5. DR Soetomo General Hospital. COVID-19 rapid screening guidelines, 2020. https://ciptadoc.com/wp-content/uploads/2020/05/alurpemeriksaan-skrining-untuk-covid-19-di-rsds.pdf. (Acceseed October $28^{\text {th }}, 2020$ ).

6. Karyono R and Wicaksana L. Current prevalence, characteristics, and comorbidities of patients with COVID-19 in Indonesia. J Community Empowerment for Health 2020; 3: 77-84.

7. Ortiz-prado E, Simbaña-rivera K, Barreno L, et al. Clinical, molecular, and epidemiological characterization of the SARS-Cov-2 virus and the coronavirus disease 2019 (COVID-19), a comprehensive literature review. Diagn Microbiol Infect Dis 2020; 98 : 115094.

8. Cadegiani A, Zimerman A, de Souza B, et al. The androcov clinical scoring for covid-19 diagnosis: a prompt, feasible, costless, and highly sensitive diagnostic tool for covid-19 based on a 1757-patient cohort. Cureus 2021; 13: e12565.

9. Bwire G. coronavirus: why men are more vulnerable to covid-19 than women. SN Compr Clin Med 2020; Jun 4: 1-3.

10. Alsohime F, Temsah M, Al-Nemri A, et al. Covid-19 infection prevalence in pediatric population : etiology, clinical presentation and outcome. J Infect Public Health 2020; 13: 1791-1796.

11. Centers for Disease Control and Prevention. (2021). Guidedance for organizing large events and gathering, 2021. https://www.cdc.gov/coronavirus/2019-ncov/community/large-events/considerations-for-events-gatherings.html. (Accessed Jan $4^{\text {th }}$, 2021).

12. Pitol A and Julian T. Community transmission of sars-cov-2 by surface: risks and risk reduction strategies. Environ Sci Technol Lett 2021 ; 8: 263-269.

13. Klopfenstein T, Kadiane-Oussou J, Toko L, et al. Features of anosmia in COVID-19. Med Mal Infec 2020; 50: 436-439.

14. Lechien J, Chiesa-Estomba D, de Siati M, et al. Olfactory and gustatory dysfunction as a clinical presentation of mild to moderate forms of the coronavirus disease: a multicenter European study. Eur Arch Otorhinolaryngol 2020; 277: 2251-2261.

15. Zhang J, Dong X, Cao Y, et al. Clinical characteristics of 140 patients infected with sars-cov-2 in Wuhan, China. Allergy 2020; 75 : 17301741.

16. Terpos E, Ntanasis-Stathopoulos I, Elalamy I, et al. Hematological findings and complications of COVID-19. Am J Hematol 2020; 95: 834-847.

17. Durrani M, Haq U, Kalsoom U and Yousaf A. Chest X-rays findings in covid 19 patients at a university teaching hospital-a descriptive study. Pak J Med Sci 2020; 36(COVID19-S4): S22-S26.

18. Stephanie S, Shum T, Cleveland H, et al. Determinants of chest radiography sensitivity for covid-19: a multi-institutional study in The United States. Radiol Cardiothorac Imaging 2020; 2: e200337.

19. Levenfus I, Ullmann E, Battegay E and Schuurmans M. Triage tools for suspected Covid-19 patients in the emergency room : aifell score. Braz J Infect Dis 2020; 24: 458-461. 